\title{
RESEARCH
}

Open Access

\section{Investigating longitudinal context-specific physical activity patterns in transition from primary to secondary school using accelerometers, GPS, and GIS}

Teun Remmers ${ }^{1,2^{*}}$ D, Dave Van Kann ${ }^{1,3}$, Stef Kremers ${ }^{3}$, Dick Ettema ${ }^{4}$, Sanne I. de Vries ${ }^{5}$, Steven Vos ${ }^{1,6}$ and Carel Thijs ${ }^{2}$

\begin{abstract}
Introduction: Previous longitudinal studies indicate that physical activity (PA) significantly declines from primary-to secondary school, and report both changes in individual and environmental determinants of PA. In order to understand this transition and to prevent this negative trend, it is important to gather contextually rich data on possible mechanisms that drive this decline. Therefore, the aim of this study was to investigate changes of PA patterns in transition between primary and secondary school, and to add domain-specific insights of how, where, and when these changes occur.
\end{abstract}

Methods: In total, 175 children participated in a 7-day accelerometer- and Global Positioning System (GPS) protocol at their last year of primary and their first year of secondary school. GPS data-points were overlaid with Geographical Information Systems (GIS) data using ArcGIS 10.1 software. Based on the GPS locations of individual data-points, we identified child's PA at home, school, local sports grounds, shopping centers, and other locations. Also, trips in active and passive transport were identified according to previously validated GPS speed-algorithms. Longitudinal multi-level linear mixed models were fitted adjusting for age, gender, meteorological circumstances, and the nested structure of days within children and children within schools. Outcome measures were minutes spent in light PA and moderate-to-vigorous PA, specified for the time-segments before school, during school, after school and weekend days.

Results: Total PA significantly declined from primary to secondary school. Although transport-related PA increased before- and during school, decreases were found for especially afterschool time spent at sports grounds and transport-related PA during weekends.

(Continued on next page)

\footnotetext{
* Correspondence: t.remmers@fontys.nl

${ }^{1}$ School of Sport Studies, Fontys University of Applied Sciences, P.O. Box 347, Eindhoven, AH 5600, The Netherlands

${ }^{2}$ Department of Epidemiology, Maastricht, Maastricht University (Medical

Center+), CAPHRI Care and Public Health Research Institute, Maastricht, the Netherlands

Full list of author information is available at the end of the article
}

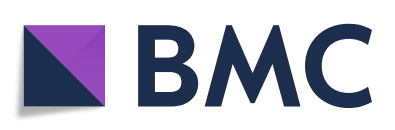

(- The Author(s). 2020 Open Access This article is licensed under a Creative Commons Attribution 4.0 International License, which permits use, sharing, adaptation, distribution and reproduction in any medium or format, as long as you give appropriate credit to the original author(s) and the source, provide a link to the Creative Commons licence, and indicate if changes were made. The images or other third party material in this article are included in the article's Creative Commons licence, unless indicated otherwise in a credit line to the material. If material is not included in the article's Creative Commons licence and your intended use is not permitted by statutory regulation or exceeds the permitted use, you will need to obtain permission directly from the copyright holder. To view a copy of this licence, visit http://creativecommons.org/licenses/by/4.0/. The Creative Commons Public Domain Dedication waiver (http://creativecommons.org/publicdomain/zero/1.0/) applies to the data made available in this article, unless otherwise stated in a credit line to the data. 


\begin{abstract}
(Continued from previous page)
Conclusions: This is the first study that demonstrated longitudinal changes of context- and domain-specific PA patterns in transition between primary and secondary school, based on device-assessed PA. Given the importance of this transition-period for the development of long-term PA patterns, results from this study warrant the development of evidence-based PA programs in this transition period, while acknowledging the integrative role of schools, parents, and afterschool sports providers. More specifically, the results underline the need to increase children's PA levels in primary schools, promote afterschool PA at secondary schools, and to prevent the drop-out in sports participation at secondary schools.
\end{abstract}

Keywords: Context, Child, Environment, Domain, Weekday, Weekend, After school, Transport, Time segment, Walking, Cycling, Sports, Geographic

\section{Background}

Insufficient physical activity (PA) and excessive sedentary behaviour in children have been consistently linked to various detrimental short- and long term consequences for health and general wellbeing, such as overweight and obesity [1], bone health [2], and mental health [3]. Despite this knowledge, children's PA levels have been found to decline from childhood to adolescence [4-8].

The transition between primary and secondary school is an important phase for PA development as changes are likely to occur in children exposure to and perceptions of the physical environment (e.g. changes in PA affordances at school ground during recess), the social environment (e.g. classmate changes), and the learning environment (e.g. more academic load). To our knowledge, four studies have longitudinally investigated PA in this transition using questionnaires [9-12], or (partly) device-assessed PA [13-17]. Four additional longitudinal studies examined PA development in 915-year-old children, but have not explicitly investigated the change between schools [18-21]. Results from studies investigating the transition from primary to secondary school are mixed. For example, six studies reported a decline $[7,11,12,17,18,20]$, while two studies exhibited an increase in PA when going to secondary school $[13,16]$.

When studying PA during the transition between primary and secondary school, it is not only essential to accurately quantify changes in children's total PA, but also to provide insight in possible mechanisms behind this potential change by using contextually rich data. It is also important to distinguish between several types of PA behaviour (i.e., behavioural domains), in order to understand changes in PA patterns and to provide meaningful starting points for intervention development [22]. This is because each PA domain has their own specific determinants $[23,24]$. When investigating specific relationships within these behavioural domains, precise measurements of PA and the context in which PA takes place are needed [25]. Most studies measured this by complementing their device-assessed PA with selfreported data (e.g., transport mode to school) [13-15, 17]. Three studies showed an increase in self-reported duration of active transport towards secondary school $[10,15,16]$, Also, several studies have suggested that changes in school environments during the transition to secondary school, are mostly explained by changes in children's active transport [10,13, 17, 26]. Marks et al. (2015) also showed that a change of school environment in the transition to secondary school was associated with less self-reported activity and active transport, but no differences were found on accelerometer measured daily PA [17]. This illustrates that an increase in one behavioural domain (e.g., transport-related PA) may not result in an increase in children's total daily PA, as this may be compensated by a decrease in another behavioural domain (e.g., organized sports participation). Above described studies showed that especially transport-related PA should be considered in interpreting PA-changes in the transition between primary and secondary school. Furthermore, Marks et al. (2015) showed disagreement of self-reported active transport versus device-assessed daily PA, which is in line with numerous previous studies that showed a lack of cohesion of results from more subjective versus device-assessed PA [27, 28]. Selfreports may be especially vulnerable to social desirability or recall bias, and extensive PA dairies cause increased participant's burden $[29,30]$. To date, studies that differentiate between various PA domains using precise and more objective measures of PA are scarce [31].

The transition between primary and secondary school can be viewed as a complex interplay between changes in individual, social and environmental factors $[15,17]$. Following a social-ecological perspective, PA patterns are also subject to political or cultural factors (e.g., transport-regulations of schools, or the existence of (after) school PA programs [32, 33]). In addition, the influence of potential determinants of PA depend on the context in which the activity occurs [24, 34, 35]. In order to understand mechanisms behind PA-changes in the transition phase between primary-and secondary school, 
it is also important to recognize the geographical context in which PA takes place and to acknowledge constraints based on time geography $[24,36]$. This may give valuable insights in the comparability of studies across various cultures and contexts, and therefore foster more meaningful international comparisons. Studies that integrate geographical and temporal information to study children's PA patterns are scarce [22, 31, 37].

Altogether, in order to understand mechanisms behind changes in PA during the transition between primary and secondary school, it is vital to accurately measure changes in PA and acknowledge a variety of contextually relevant behavioural PA domains based on information from time geography and geographical location. Studies combining accelerometers and GPS loggers may be a valuable contribution to unravel changes in specific PA domains in transition from primary to secondary school. Recent studies showed that it is feasible to passively monitor continuous PA and location data, by combining accelerometers and Global Positioning System (GPS) data [31]. When integrated with Geographical Information Systems (GIS), the behavioural domain, as well as the context of PA can be inferred from its geographical location or travel speed [38-41].

Consequently, the aim of this study was to investigate changes in PA patterns within device-assessed behavioural contexts in the transition between primary and secondary school, to add in-depth insight on how, where, and when changes in PA patterns occur. In addition, literature suggests that changes between primary and secondary school are partly explained by active transport to school. Our secondary aim was therefore to gain further insight in the role of transport-related PA during this transition.

\section{Methods}

\section{Design and participants}

The present study was embedded in the Physical Activity in Public Space Environments (PHASE) study, which was specifically set up to examine longitudinal relationships between characteristics of the physical environment and children's PA patterns in the transition phase from primary to secondary schools. Children's PA patterns were investigated at baseline (last year primary school) and follow-up (first year of secondary school). Measurements were conducted in the municipality of 'sHertogenbosch, the Netherlands, which covers around $110 \mathrm{~km}^{2}$ flatland, and has approximately 150.000 residents [42] (see Additional file 1). Population density varies between neighbourhoods $(1.8 ; 59.0$ residents per hectare). Average population density of included neighbourhoods was 19.4 residents per hectare [43]. At baseline, we invited 30 primary schools to participate, of which 20 schools agreed. All children in their final year (approximately 1000 children) were invited to participate in our study, 341 children provided informed consent to participate in baseline measurements. One year later, all children changed schools. Participating children were approached again in secondary school for a follow-up measurement using the same protocol. Ethical approval for the PHASE study was obtained from the research ethics committee of the Maastricht University Medical Centre (reference number 12-4-077). From all participating children, the child and parents provided informed consent.

Data were collected from April till July 2015 for baseline measurements and April till July 2016 for the follow-up measurement, with an average daily temperature of 15.1 degrees Celsius $(\mathrm{SD}=5.0)$ and $77 \%$ of the days with $<1.0 \mathrm{~mm}$ of precipitation (based on registries from a local weather station). Sunset times during this time-period were between 20:13 and 22:06 h local time in the center of the Netherlands (data extracted from http://www.timeanddate.com/sun/ netherlands). Accelerometers and GPS loggers were distributed during classroom visits, where children received verbal and written instruction about how to wear the devices. Both devices were attached to the waist and worn at the right hip with a single elastic belt. Measurement protocol included wearing the devices during waking hours for 7 consecutive days, only to remove the belt during water-related activities (e.g., swimming, showering), and to recharge the GPS logger overnight. In addition, children were asked to record the times and reasons why they took off the devices in a diary. After measurement, devices were collected by the researchstaff during school hours, while the child and one of their parents received a verbal and written invitation for an electronic questionnaire.

\section{Measurement \\ Socio-demographic measures}

At baseline, directly after PA measurement, children and parents filled in an electronic questionnaire focusing on aspects such as birth date, address, perceived physical environment, child's PA, transportation habits and homework (response rate 77 and $75 \%$ for the children and parents, respectively). We assessed whether children from divorced parents were residing at two locations, and whether children potentially moved home between baseline and follow-up measurements. Schools provided detailed class timetables for the data-collection period.

\section{Accelerometer and GPS loggers}

In this study, accelerometers (GT3X, ActiGraph, Pensacola, Florida) were set to record data at $10 \mathrm{~s}$ epochs. Actilife version 6.11.9 was used for initialization and downloading. The GPS logger used in this study 
(BT-Q1000XT, Qstarz International Co, Taipei, Taiwan) showed relatively good static spatial accuracy compared to other units [44], and acceptable dynamic accuracy [45]. The manufacturer's software QTravel version 1.46 was used for initialization and downloading of GPS loggers. The loggers were set to record data at $10 \mathrm{~s}$ epochs while recording parameters such as date, time, longitude, latitude, and speed. GPS devices stopped logging data when storage capacity was full [22].

\section{Data analysis}

\section{Data management}

Accelerometer and GPS data were processed using the Personal Activity and Location Measurement System (PALMS), which allows users control over most parameter settings in a web-based application $[41,46]$. In order to handle the data-load, data were processed in PALMS separately for each school and time-point (i.e. baseline and follow-up). PALMS categorized intensity of accelerometer activity into sedentary time (ST), light PA (LPA), moderate PA (MPA), and vigorous PA (VPA) according to Evenson's cut-points [47], which are based on freeliving activities of 5-15 year-old children [48]. We defined non-wear time as $\geq 20$ consecutive minutes of zero counts [49]. Datasets were cleaned based on extreme speed (i.e. threshold $\geq 130 \mathrm{kmph}$ ) and changes in elevation (i.e. threshold $\geq 1000 \mathrm{~m}$ ). Algorithms as described in Carlson et al. (2015) were used for trip and trip mode classification (e.g., pedestrian, bicycle) [40]. As the sample in the study of Carlson et al. (2015) consisted of commuting cyclists that were expected to accumulate higher cycling speeds, the present study deviated from these thresholds by using the $10-25 \mathrm{kmph}$ bicycling speed-threshold. Invalid GPS points were imputed from the last known valid point, for up to $10 \mathrm{~min}$. Finally, PALMS matched accelerometry and GPS data based on start- and end-times of the GPS logger. Subsequently, we combined school-specific datasets into multiple PostgreSQL databases (http://www.postgresql.com), where we performed additional queries to identify before school (i.e. 6: $00 \mathrm{AM}$ - start school time), during school(i.e. based on individual school's schedules), and after school time-segments (i.e. end school time - 11:59 PM). Additionally, we also included data on weekend days. This resulted in eight time-segmented datasets (i.e. before school, during school, after school and weekend days at both primary and secondary school), where days were the unit of analyses.

\section{Spatial analyses}

Time-segmented datasets were integrated into ArcGIS version 10.4.1 (ESRI, Redlands, California), where we overlaid GIS-data from the municipality of 's-Hertogenbosch. We used a stepwise selection procedure to identify data-points occurring in various contexts, based on the GPS-derived contexts of Klinker et al. (2014) [22] and the Sensewear-derived contexts of De Baere et al. (2015) [16]. First, we identified each child's home and school parcel, using ArcGIS geocode-functionality and the municipality's address-database (see Additional file 1). We then identified the context 'home' and 'school' by selecting data-points (i.e., records) that were within $10 \mathrm{~m}$ of each child's home-parcel. Secondly, from the remaining records $>10 \mathrm{~m}$ from a child's home and school parcels, we identified the other contexts by selecting data-points within $10 \mathrm{~m}$ from sports grounds, commercial/shopping centers or malls, and afterschool care parcels. Third, from the remaining records $>10 \mathrm{~m}$ from these more specific parcels, we applied the above-described PALMS speedthresholds in order to identify transport-related PA. Fourth, records that were not selected in the above stepwise procedure, were defined as records at other locations (e.g. at friend's homes or at parks).

\section{Data reduction}

First, we selected children with longitudinal follow-up data in the transition from primary to secondary school (Fig. 1). Subsequently, data from children that moved home between baseline and follow-up measurements, and with more than one home environment (often in the case of co-parenting) was omitted. Data-points with extremely high accelerometer counts (i.e. $>9498$ counts per minute) were also omitted. Subsequently, raw data-points were aggregated into daily totals, segregated by specific timesegments of the day (Fig. 1). As preliminary inspection of the data showed that children only spent little time at afterschool childcare and at commercial/shopping centers, we re-defined these contexts as time spent in other locations. In accordance with previous studies investigating time-segmented PA [50-52], we ensured reliability of the time-segments during school, afterschool and weekend by only selecting records from days with $\geq 50 \%$ of the potential wear time. For example, for children from schools that end at 4:00 PM, potential afterschool wear time is 8 hours (as data logging starts ends at 11:59 PM). This results in wear time criteria of at least 240 min of wear time in this specific time segment. Time before school data was included when at least $30 \mathrm{~min}$ of combined GPS and accelerometer data was available in that time segment, as this was considered the minimum amount of time children need to prepare for, and travel to school [53]. Finally, we combined baseline and follow-up data in four longitudinal datasets (i.e., before school, during school, after school and at weekend days; Fig. 1).

\section{Statistical analyses}

After describing changes in total PA in the transition between primary and secondary school, we conducted 


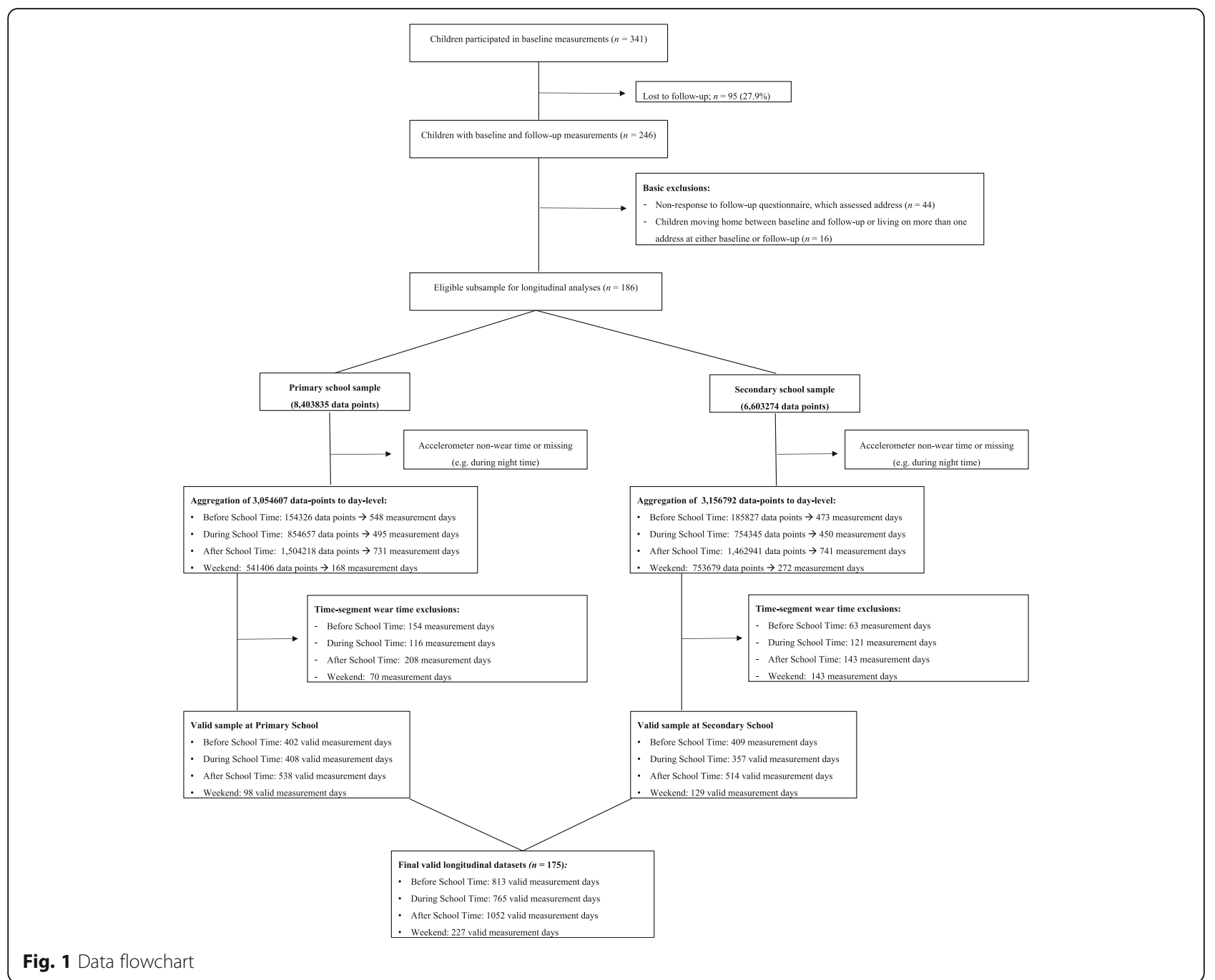

analyses on the average number of minutes for the time that children contributed to context-specific light PA (LPA) and moderate-to-vigorous PA (MVPA), both in primary school and secondary school. Days with no accelerometer data on specific contexts (e.g., at school during weekends) were assigned zero minutes of PA to that context. In subsequent multivariate models, days were used as the unit of analyses and the main explanatory variable was the index-variable that represented either baseline- or follow-up measurement. All multivariate analyses were performed using longitudinal multilevel linear mixed models, acknowledging the two-level structure of primary-secondary school transition within multiple repeated days and repeated days within children. We modeled this within-subject change between primary and secondary school by adjusting for the interaction between the index-variable defining baseline- or follow up measurements, a variable counting the number of repeated days of measurement within a child and the unique identifying variable for each child. No further covariance between days within children was assumed. Furthermore, a random slope variable was used to account for clustering of children within schools, using a variance component covariance structure. Outcome variables were minutes of LPA and MVPA (specified for each time-segment and context). Model fit and normality of residuals of these multivariate models were inspected to verify its fitting capabilities. In contexts with a relative overrepresentation of zero counts due to non-wear time, non-parametric negative binomial models were applied to estimate change in minutes of LPA and MVPA between primary- and secondary school. However, some contexts still consisted of too few data-points (e.g. during weekend days at the school's parcel) and were therefore not presented.

Children sometimes reported that they removed devices at random activities throughout the day because they thought the devices were uncomfortable, they were afraid of damaging the devices or when they stayed at home late in the evening. As these activities were not 
specifically related to PA or inactivity, we hypothesized that non-wear time may not be significantly different from wear time. In addition, we were interested in the total duration of PA patterns performed at specific contexts and whether these patterns would change during the transition. Therefore, we adjusted our multivariate analyses for total daily wear time instead of contextspecific wear time. Based on registries from local weather stations, we extracted hourly meteorological data for each day of PA measurement. We computed daily averages of meteorological data, and we adjusted for these meteorological circumstances in subsequent multivariate analyses. Statistical analyses were performed using SPSS 21.0 for Windows (IBM SPSS Inc., Armonk, $\mathrm{NY}$ ), and $p<0.05$ indicated statistical significance.

\section{Results}

\section{Participant characteristics and development of total PA}

From the 341 participating children in primary school, 246 children (72\%) also participated 1 year later in secondary school. From these children, $186(75,6 \%)$ filled in the questionnaire in secondary school and did not move home (Fig. 1). In total, valid data were provided by 89 boys and 86 girls who attended 20 primary schools and 10 secondary schools. Children were averagely aged 12.1 $(\mathrm{SD}=0.4)$ years old at baseline. Parents from participating children had relatively high socio-economic status; $72 \%$ with secondary vocational or higher educational diploma, and $67.9 \%$ with a paid job for at least 3 days per week. On average, children lived $620(\mathrm{SD}=571)$ meters from their primary school and $3127(\mathrm{SD}=1976)$ meters from their secondary school. Based on the standardized social economic status score of $0.06(\mathrm{SD}=1.3)$ neighborhood SES of our participants were comparable with the national average [37].

While attending primary schools, children performed more time in MVPA during weekend days compared to weekdays (55.1 versus $43.9 \mathrm{~min} /$ day, respectively). Total MVPA declined in secondary school, both during weekend days (from 55.1 to $34.3 \mathrm{~min} /$ day), and during weekdays (from 43.9 to $34.0 \mathrm{~min} /$ day). Comparable declines were found in LPA. On weekdays, boys exhibited significantly more MVPA at both primary-and secondary school compared to girls, while girls performed more LPA at primary school only. No significant gender differences were found on weekend days (Table 1). When looking at more specific PA domains, declines from primary to secondary were predominantly found in the afterschool period. Namely, children exhibited $27.7 \mathrm{~min}$ of MVPA (6.8\% from afterschool weartime) in primary-, while $18.4 \mathrm{~min}(4.4 \%)$ were accumulated in secondary school. Smaller declines were found for MVPA during school time ( 15.5 versus $13.6 \mathrm{~min} /$ day). In contrast to this general decline of PA in secondary school, we found that especially LPA increased before school time (30.4 versus $39.0 \mathrm{~min} /$ day). Boys exhibited significantly more MVPA during- and afterschool time than girls, both at primary and secondary school. Also, boys showed significantly more LPA before- and during school time, in primary school only. This was partly different for girls, who exhibited significantly more LPA afterschool time at primary and secondary school, and more LPA before school time, in secondary school only (Table 1 ).

\section{Context-specific PA patterns in primary and secondary school}

During school time, children spent more time outside school grounds in secondary school, while at primary school, children spent more time on the school grounds. On school grounds, the relative intensity of PA was stable, while outside school grounds percentages of LPA and MVPA declined. In the afterschool period, time spent at home increased with an average of about $50 \mathrm{~min}$ in secondary school, while LPA and MVPA performed at home was relatively stable. During afterschool periods, sports grounds were visited less frequently, leading to an average decline of approximately $8.5 \mathrm{~min}$ of wear time per day at sport grounds, which in turn resulted in declines of both LPA and MVPA (12.3 versus $9.6 \mathrm{~min} /$ day and 6.5 versus $4.6 \mathrm{~min} /$ day, respectively). In addition, time spent in LPA at other locations decreased with approximately $25 \mathrm{~min}$ in the afterschool period, as did MVPA (9.5 versus $5.1 \mathrm{~min} /$ day). During weekend days, relatively small declines in both LPA and MVPA were found across various locations (Table 2).

\section{Transport-related (in) activity patterns in primary and secondary school}

We identified records as transport-related (in) activity when 1) records occurred $>10 \mathrm{~m}$ from home, school, sports grounds, commercial/shopping centers or afterschool care parcels, and 2) records met the GPS-based trip detection algorithms as either active transport (i.e., walking or cycling) or passive transport. Before school time, active transport increased in secondary school, which led to an increase in LPA (3.8 versus $11.5 \mathrm{~min} /$ day). In contrast, transport-related PA remained relatively stable during- and afterschool time. During weekend days however, we found a decline in transportrelated LPA (19.4 versus $10.1 \mathrm{~min} /$ day) and MVPA (11.2 versus $7.6 \mathrm{~min} /$ day). We also found small declines in the use of passive transport in the transition period. Gender differences were found in the afterschool period, where girls showed significantly more LPA in active transport, whereas boys showed significantly more MVPA in active transport (Table 3). 


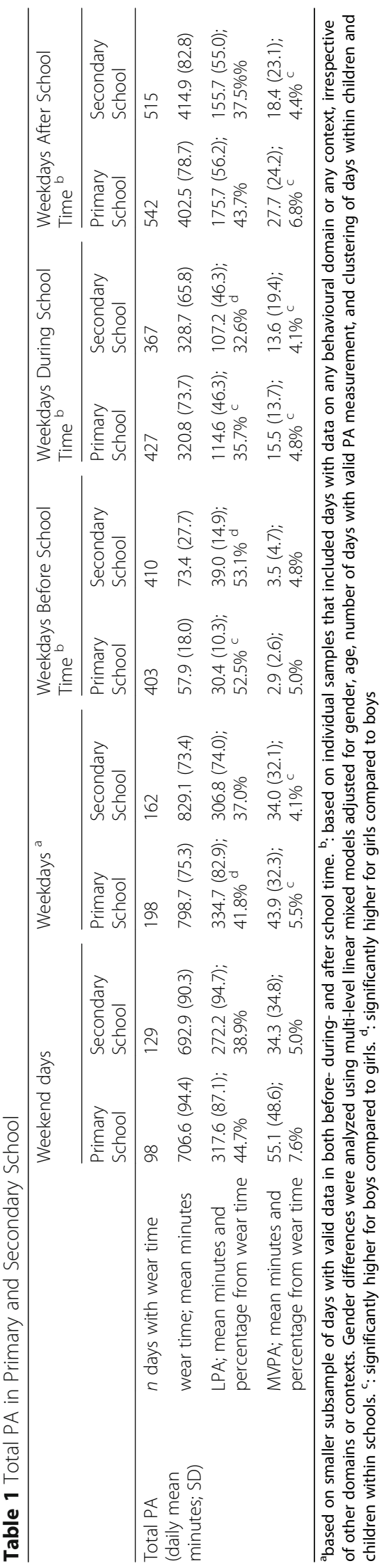




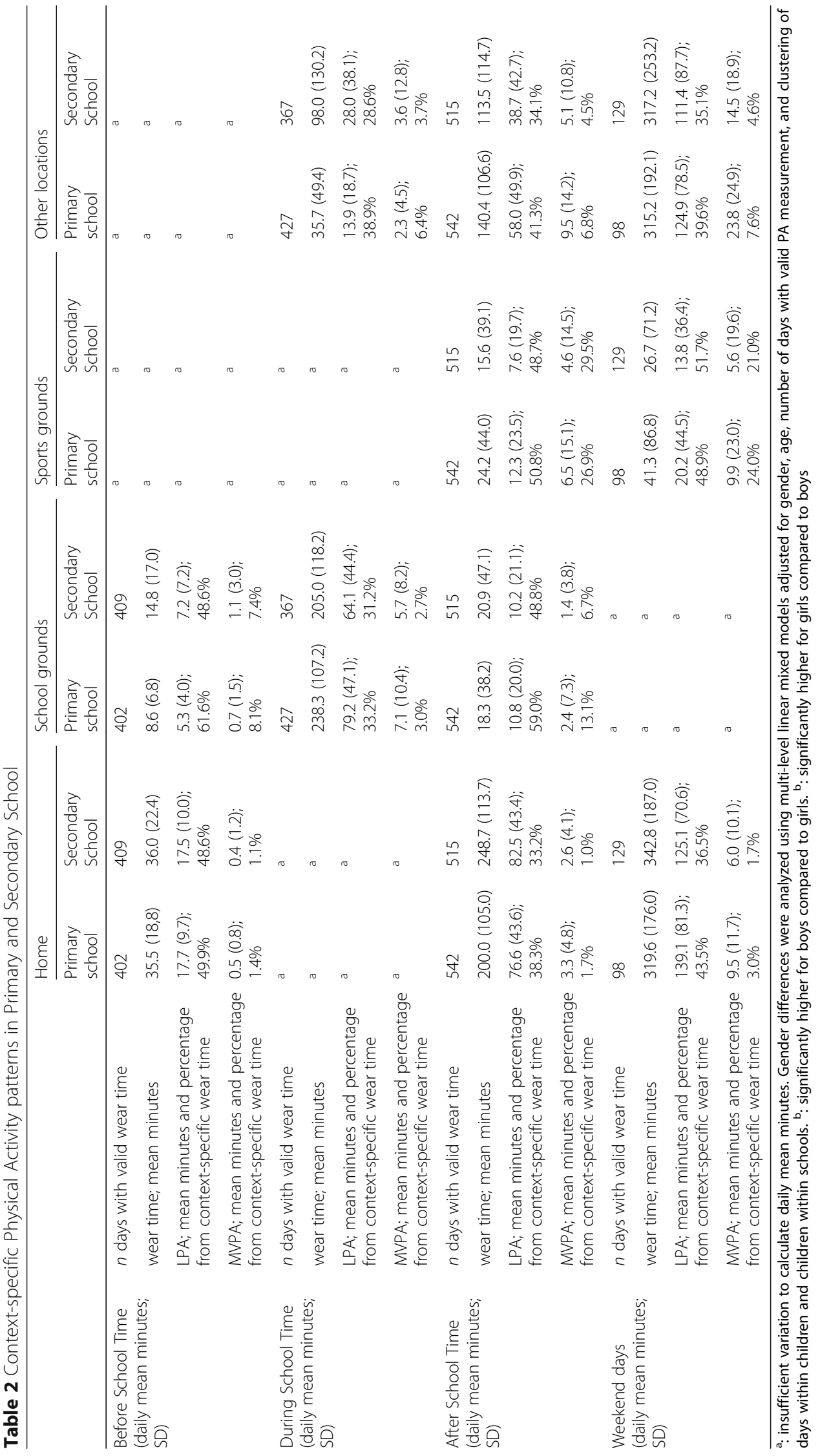


Table 3 Transport-related (in) activity patterns in Primary and Secondary School

\begin{tabular}{|c|c|c|c|c|c|}
\hline & & \multicolumn{2}{|l|}{ Active transport } & \multicolumn{2}{|l|}{ Passive transport } \\
\hline & & Primary school & Secondary School & Primary school & Secondary School \\
\hline \multirow{4}{*}{$\begin{array}{l}\text { Before School Time } \\
\text { (daily mean minutes; SD) }\end{array}$} & $n$ days with valid wear time & 403 & 410 & 403 & 410 \\
\hline & wear time in transport; mean minutes & $3.8(3.8)$ & $11.5(8.5)$ & $0.9(3.6)$ & $0.8(3.0)$ \\
\hline & $\begin{array}{l}\text { LPA; mean minutes and percentage from } \\
\text { transport-related PA }\end{array}$ & $\begin{array}{l}2.8(3.3) \\
73.7 \%\end{array}$ & $\begin{array}{l}8.9(7.6) \\
77.4 \%\end{array}$ & $\begin{array}{l}0.4(1.4) \\
44.4 \%\end{array}$ & $\begin{array}{l}0.3(1.4) \\
37.5 \%\end{array}$ \\
\hline & $\begin{array}{l}\text { MVPA; mean minutes and percentage } \\
\text { from transport-related PA }\end{array}$ & $\begin{array}{l}0.7(1.5) ; \\
18.4 \%\end{array}$ & $\begin{array}{l}0.7(2.2) ; \\
6.1 \%{ }^{c}\end{array}$ & a & a \\
\hline \multirow{4}{*}{$\begin{array}{l}\text { During School Time } \\
\text { (daily mean minutes; SD) }\end{array}$} & $n$ days with valid wear time & 427 & 367 & a & a \\
\hline & wear time in transport; mean minutes & $8.0(11.4)$ & $7.2(11.8)$ & a & a \\
\hline & $\begin{array}{l}\text { LPA; mean minutes and percentage from } \\
\text { transport-related PA }\end{array}$ & $\begin{array}{l}4.5(6.7) ; \\
56.3 \%\end{array}$ & $\begin{array}{l}5.2(8.6) ; \\
72.2 \%\end{array}$ & a & a \\
\hline & $\begin{array}{l}\text { MVPA; mean minutes and percentage } \\
\text { from transport-related PA }\end{array}$ & $\begin{array}{l}1.7(3.4) \\
21.3 \%\end{array}$ & $\begin{array}{l}1.1(4.6) ; \\
15.3 \%\end{array}$ & a & a \\
\hline \multirow{4}{*}{$\begin{array}{l}\text { After School Time } \\
\text { (daily mean minutes; SD) }\end{array}$} & $n$ days with valid wear time & 542 & 515 & 542 & 515 \\
\hline & wear time in transport; mean minutes & $21.1(19.8)$ & $20.8(21.8)$ & $10.9(19.6)$ & $7.9(19.5)$ \\
\hline & $\begin{array}{l}\text { LPA; mean minutes and percentage from } \\
\text { transport-related PA }\end{array}$ & $\begin{array}{l}13.4(13.5) \\
63.5 \%\end{array}$ & $\begin{array}{l}14.3(14.4) ; \\
68.8 \%^{c}\end{array}$ & $\begin{array}{l}4.7(8.9) ; \\
43.1 \%\end{array}$ & $\begin{array}{l}3.0(6.8) ; \\
38.0 \%{ }^{c}\end{array}$ \\
\hline & $\begin{array}{l}\text { MVPA; mean minutes and percentage from } \\
\text { transport-related PA }\end{array}$ & $\begin{array}{l}5.1(8.3) \\
24.2 \%\end{array}$ & $\begin{array}{l}4.4(11.9) ; \\
21.2 \%{ }^{b}\end{array}$ & a & a \\
\hline \multirow{4}{*}{$\begin{array}{l}\text { Weekend days } \\
\text { (daily mean minutes; SD) }\end{array}$} & $n$ days with valid wear time & 89 & 129 & 89 & 129 \\
\hline & wear time in transport; mean minutes & $35.1(34.9)$ & $18.7(21.8)$ & $36.1(47.1)$ & $35.8(49.8)$ \\
\hline & $\begin{array}{l}\text { LPA; mean minutes and percentage from } \\
\text { transport-related PA }\end{array}$ & $\begin{array}{l}19.4(26.1) \\
55.3 \%\end{array}$ & $\begin{array}{l}10.1(13.3) \\
54.0 \%\end{array}$ & $\begin{array}{l}14.2(19.3) \\
39.3 \%\end{array}$ & $\begin{array}{l}12.2(16.4) ; \\
34.1 \%\end{array}$ \\
\hline & $\begin{array}{l}\text { MVPA; mean minutes and percentage from } \\
\text { transport-related PA }\end{array}$ & $\begin{array}{l}11.2(16.0) \\
32.1 \%\end{array}$ & $\begin{array}{l}7.6(13.6) ; \\
40.6 \%\end{array}$ & $\mathrm{a}$ & $\mathrm{a}$ \\
\hline
\end{tabular}

a: insufficient variation to calculate daily mean minutes. Gender differences were analyzed using multi-level linear mixed models adjusted for gender, age, number of days with valid PA measurement, and clustering of days within children and children within schools. ${ }^{\text {b: }}$ significantly higher for boys compared to girls.

$c_{\text {: significantly higher for girls compared to boys }}$

Changes in context-specific PA patterns and transportrelated (in) activity from primary to secondary school

In Table 4, we explained changes of children's contextspecific PA patterns between primary and secondary school using multivariate models. Before school, children accumulated 6.34 more daily LPA minutes in active transport. During school, total LPA declined with approximately $11 \mathrm{~min} /$ day. More specifically, we found that LPA and MVPA at other locations increased in secondary school (14.39 $\mathrm{min} /$ day and $2.38 \mathrm{~min} /$ day, respectively). In contrast, LPA at school grounds decreased during school (-18.96 min/day). In afterschool periods, total LPA and MVPA declined (-25.04 $\mathrm{min} /$ day and $-7.98 \mathrm{~min} /$ day, respectively). More specifically, LPA and MVPA decreased significantly at other locations $(-21.20 \mathrm{~min} /$ day and $-5.20 \mathrm{~min} /$ day, respectively). Furthermore, we found small decreases in LPA at sports grounds $(-3.54 \mathrm{~min} /$ day $)$ and MVPA at school grounds (-1.05 min/day). During weekend days, the above described declines of total LPA and MVPA were no longer statistically significant in the adjusted model. Furthermore, LPA in active transport decreased with $15.88 \mathrm{~min}$ during an average weekend day, while changes in transport related MVPA were not significant. Children's passive transport slightly decreased beforeand after school ( $-0.43 \mathrm{~min} /$ day and $-1.65 \mathrm{~min} /$ day $)$ (Table 4).

\section{Discussion}

To our knowledge, this was the first study using combined accelerometer, GPS and GIS data to investigate longitudinal associations of PA patterns in the transition phase from primary to secondary school, in order to add in-depth insights of how, where and when changes occur. We found a substantial decline of PA in transition from primary to secondary school. The decline however did not occur evenly across daily time periods and locations. Whereas total daily PA declined, transport-related PA during weekdays increased. Children showed notable declines in PA performed at sports grounds and at other locations.

Several results were in line with findings of previous studies, which were based on self-reported or deviceassessed data. First, in line with studies reporting increases in overall self-reported transport-related PA in transition to secondary school $[10,13,15,16]$, we also 


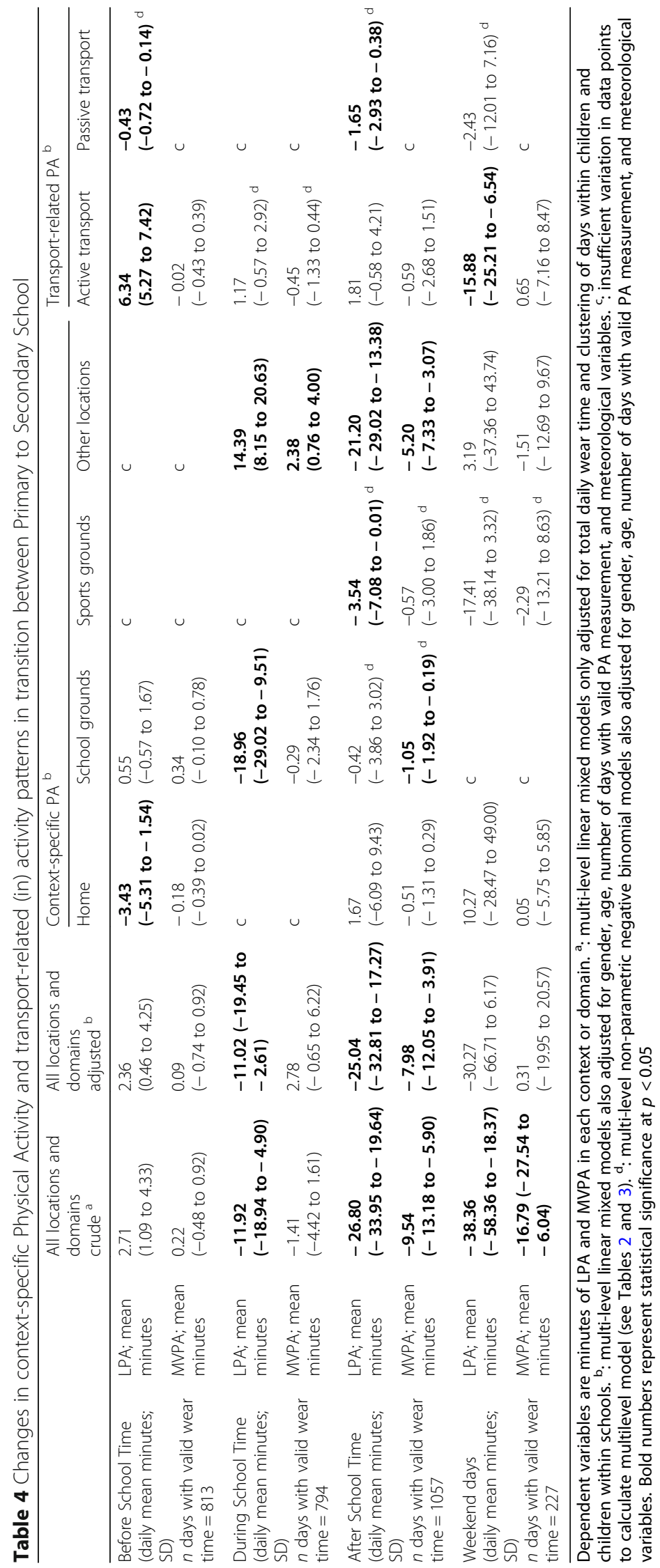


found an increase in time spent in active transport, especially before school. This increase in transport-related PA may be a result of parents providing these children with more independent mobility as they get older. However, as in our sample we found that transport-related PA significantly declined during weekends in secondary school, increased transport-related PA in our sample was probably related to the increased distance between home and school. Children with increased transportrelated PA during weekdays may have compensated this with declines of afterschool LPA at other locations or with declining participation in organized sports. As investigating compensation mechanisms was not the primary purpose of this paper, future research using detailed within-person designs and larger samples are needed to unravel compensation mechanisms in context-specific PA patterns. The present study contributes by providing in-depth insights in changes of daily PA patterns in transition between primary-and secondary school, in terms of location, time and domainspecific behaviour [13, 17, 54, 55]. Furthermore, this study shows that when investigating determinants of PA patterns in school-aged children, weekday and weekend day patterns differ, for example a by varying contribution of transport-related PA to their PA pattern. This is in line with theories of space-time geography and activity-space approach, which contemplate that PA patterns are partly shaped by time-constraints, social influences and by exposure to environments attributes in their own activity-space [24, 36]. As the activity-space and time-constraints of children during weekends may be fundamentally different from weekdays, segregation of these days is vital in understanding determinants of children's PA patterns. In addition, future studies are encouraged to include more meaningful behavioural domains using geographical, cultural or temporal contexts, in order to understand changes in PA patterns and to foster international comparisons of PA-promoting initiatives.

Second, we found that total LPA during school time declined in secondary school, which supports conclusions of a 3-year follow-up study of Harding et al. (2015) [18] who reported parallel decreases of LPA during school, after school, and in weekends, but contrasts results of a 4-year follow-up study of Brooke et al. (2014) [20]. Also, the number of minutes spent in MVPA during school hours was comparable with previous studies in this age group $[16,56]$. Our study showed that during school hours, more time was spent outside school grounds. This resulted in increased LPA and MVPA outside school grounds but on the other hand decreased LPA at school grounds. This may be related to children performing educational activities outside the school's geographical parcel, such as surrounding neighborhoods or parks. Although the relative contribution to daily total MVPA during weekdays was slightly higher, we found a decline in the average minutes of MVPA that children spent at schoolgrounds. As emerging evidence links daily PA to academic performance [57-59] and when taking into account the general decline of PA across contexts and locations, schools are encouraged to utilize their potential for increasing PA during- and after school hours at school grounds, for example by providing physical education or afterschool PA opportunities. When attending primary school, but especially after the transition to secondary school, we found that sports grounds are also important in the accumulation of MVPA. This stresses the need to prevent further drop out in sports participation in secondary school children to prevent further decreases in MVPA during adolescence.

Third, in line with our finding that total LPA and MVPA declined in the transition-period, we found that afterschool LPA and MVPA also declined in secondary school, which supports conclusions from three studies $[14,18,20]$. These findings are also in line with selfreported data of three studies that suggested increased time spent on homework, leisure time TV and computer use in transition to secondary school [15-17]. Our study adds that changes in after school PA were predominantly due to a decrease of PA performed at home and other locations (e.g. at friend's homes or at parks).

\section{Strengths and weaknesses}

A study strength is the utilization of GPS devices in order to investigate associations between the deviceassessed context-specific PA patterns. Moreover, the longitudinal design, as well as the in-depth analyses of a naturally occurring, important transition in the development of children's PA patterns may be considered a strength of the study. However, this study also has some weaknesses. First, in order to reduce complexity of associations, analyses were conducted on a subsample (i.e. non-movers and living at a single address). Due to period-specific wear time validation criteria and by the specificity of our context-specific analyses, the amount of measurement-days in our analyses was further reduced. This limited our statistical power, especially in multilevel models. Attrition analyses revealed that total PA of our final sample was generally comparable with larger sample of children providing device-assessed data on any day, both in terms of cross-sectional and longitudinal comparisons. Only the average minutes of LPA and MVPA performed during weekend days and LPA performed after school was slightly higher in our final subsample compared to the larger sample (Additional file 3). Another important issue in analyzing context-specific PA data is that by theory, a child's daily individual PA pattern consists of multiple interacting 
contexts. As a consequence, increases of PA spent in one context by definition results in fewer time/opportunities to perform PA in another context [60]. In contrast to this more individually based compositional approach, the present study applied a more contextcentered approach to provide insights of how children's general PA patterns performed at various contexts change during transition from primary to secondary school.

Another limitation of this study was the specificity of our time-segment during school. This may be improved by also defining recess time and/or physical education lessons $[20,61]$. As we found that children spent considerable time outside school grounds during school time, more specific information regarding activities during recess, or trips to externally located physical education facilities may have improved our understanding of these behaviours. Finally, we found that active transport plays an important role in reducing the negative impact of PA in secondary school. In contrast to findings of other studies [62, 63], increases in active transport predominantly resulted in higher LPA (and not MVPA). This may be a result of relatively higher contribution of cycling trips to total transport-related PA instead of walking trips (due to increased distance between home and school) and the tendency of our hip-worn ActiGraph GT3X+ accelerometers to underestimate the workload of especially cycling trips [64]. Furthermore, future studies may investigate transport-related PA patterns even more specifically by identifying start- and endpoints of a trip. For example, such studies could specifically investigate determinants of children's daily active- versus passive transportation modes between home and school [62].

Generalizability of this study may be limited to samples with comparable cultural and infrastructural circumstances. For example, in the Netherlands, there are no organized passive transport programs in place (e.g. school busses) and the environment is generally supportive for active transport (e.g. absence of hills, high availability and quality of cycling paths, bike sheds at schools). This may increase the likelihood of active transport in the homeschool commute, regardless of the distance between home and school. In addition, parental motives regarding independent mobility and accompanied feeling of neighbourhood safety may be different from other international samples [65]. Also, time-constrains of children due to competing activities such as organized sports participation or homework may also be considered in comparing results with other studies [36].

\section{Conclusion}

This is the first study that demonstrated device-assessed longitudinal changes of context- and domain-specific PA patterns in transition between primary and secondary school. We found that overall PA significantly declined from primary to secondary school. Furthermore, we showed that although transport-related PA increased before and during school, especially afterschool PA spent sports grounds, afterschool PA spent at other locations, and transport-related PA during weekends decreased in transition from primary to secondary school. Given the importance of this transition-period for the development of long-term PA patterns, results from this study warrant the development of evidence-based PA programs in this transition period, while acknowledging the integrative role of schools, parents, and afterschool sports providers. More specifically, we emphasize the need to increase children's PA levels in primary schools, promote afterschool PA at secondary schools, and to prevent the drop-out in sports participation at secondary schools.

\section{Supplementary information}

Supplementary information accompanies this paper at https://doi.org/10. 1186/s12966-020-00962-3.

Additional file 1. Geographical distribution of participating primary and secondary schools in the municipality of 's-Hertogenbosch, the Netherlands.

Additional file 2. STROBE checklist.

Additional file 3. Attirition analyses.

\begin{abstract}
Abbreviations
PA: Physical activity; ST: Sedentary time; LPA: Light physical activity; MPA: Moderate physical activity; VPA: Vigorous physical activity; MVPA: Moderate-to-vigorous physical activity; GPS: Global positioning system; GIS: Geographical information system; PALMS: Personal Activity and Location Measurement System; PHASE: Physical activity in public space environments
\end{abstract}

\section{Acknowledgements}

Authors acknowledge the assistance of Tim Schepers, Marieke Obbes and Veerle van den Heuvel in the measurements. Finally, we would like to thank participating schools, children and parents, as well as the assistance from the municipality.

\section{Authors' contributions}

Study concept and design: TR, DE, SDV, CT, SK. Acquisition of data: TR, CT, SK, Analysis and interpretation of data: TR, DVK, CT. Drafting of the manuscript: TR, DVK, CT, SK. Critical revision of the manuscript for important intellectual content: SDV, DE, SV. Funding Acquisition: DE, SDV, SK, CT. The authors have read and approved the final version of the manuscript.

\section{Funding}

This study was funded by the Netherlands Organization for Scientific Research (NWO, programme Sports and Physical Exercise, grant no. 328-98005). The funders had no role in study design, data collection, statistical analysis or preparation of this manuscript.

Availability of data and materials

The datasets used and/or analyzed during the current study are available from the corresponding author on reasonable request.

Ethics approval and consent to participate

Ethical approval for the PHASE study was obtained from the research ethics committee of the Maastricht University Medical Centre (reference number 12-4-077). All participating children and parents provided informed consent. 


\section{Consent for publication}

Not applicable.

\section{Competing interests}

The authors declare that they have no competing interests.

\section{Author details}

'School of Sport Studies, Fontys University of Applied Sciences, P.O. Box 347, Eindhoven, AH 5600, The Netherlands. ${ }^{2}$ Department of Epidemiology, Maastricht, Maastricht University (Medical Center+), CAPHRI Care and Public Health Research Institute, Maastricht, the Netherlands. ${ }^{3}$ Department of Health Promotion, Maastricht University (Medical Center+), NUTRIM School of Nutrition and Translational Research in Metabolism, Maastricht, the Netherlands. ${ }^{4}$ Department of Human Geography and Planning, Utrecht University, Utrecht, the Netherlands. ${ }^{5}$ The Hague University of Applied Sciences, Research group Healthy Lifestyle in a Supporting Environment, The Hague, the Netherlands. ${ }^{6}$ Department of Industrial Design, Eindhoven University of Technology, Eindhoven, The Netherlands.

\section{Received: 27 December 2019 Accepted: 27 April 2020}

\section{Published online: 18 May 2020}

\section{References}

1. Strong WB, Malina RM, Blimkie CJ, Daniels SR, Dishman RK, Gutin B, et al. Evidence based physical activity for school-age youth. J Pediatr. 2005;146(6):732-7.

2. Boreham CAG, McKay HA. Physical activity in childhood and bone health. $\mathrm{Br}$ J Sports Med. 2011;45(11):877-9.

3. Biddle SJ, Asare M. Physical activity and mental health in children and adolescents: a review of reviews. Br J Sports Med. 2011;45(11):886-95.

4. Telama R. Tracking of physical activity from childhood to adulthood: a review. Obes Facts. 2009;36(11):1937-43.

5. Kristensen PL, Møller N, Korsholm L, Wedderkopp N, Andersen LB, Froberg K. Tracking of objectively measured physical activity from childhood to adolescence: the European youth heart study. Scand J Med Sci Sports. 2008; 18(2):171-8.

6. Nader PR, Bradley RH, Houts RM, McRitchie SL, O'Brien M. Moderate-tovigorous physical activity from ages 9 to 15 years. JAMA. 2008;300(3):295-305.

7. Corder K, Sharp SJ, Atkin AJ, Griffin SJ, Jones AP, Ekelund U, van Sluijs EM. Change in objectively measured physical activity during the transition to adolescence. Br J Sports Med. 2015;49(11):730-6.

8. Dumith SC, Gigante DP, Domingues MR, Kohl HW. Physical activity change during adolescence: a systematic review and a pooled analysis. Int J Epidemiol. 2011;40(3):685-98.

9. Rutten C, Boen F, Seghers J. Changes in physical activity and sedentary behavior during the transition from elementary to secondary school. J Phys Act Health. 2014;11(8):1607-13.

10. Cardon GM, Maes LR, Haerens LL, De Bourdeaudhuij IM. Bicycling to school during the transition from childhood into adolescence: a six-year longitudinal study. Pediatr Exerc Sci. 2012;24(3):369-83.

11. Inchley JC, Kirby JLM, Currie C. Physical activity in Scottish schoolchildren (PASS) project: physical activity among adolescents in Scotland: final report of the PASS study: child and adolescent Health Research unit (CAHRU); 2008.

12. Niven A, Fawkner S, Knowles A, Henretty J. From primary to secondary school: changes in Scottish girls' physical activity and the influence of maturation and perceptions of competence. Edinburgh: School of Life Sciences Heriot Watt University; 2009.

13. Cooper AR, Jago R, Southward EF, Page AS. Active travel and physical activity across the school transition: the PEACH project. Med Sci Sports Exerc. 2012;44(10):1890-7.

14. Jago R, Page AS, Cooper AR. Friends and physical activity during the transition from primary to secondary school. Med Sci Sports Exerc. 2012; 44(1):111-7.

15. De Meester F, Van Dyck D, De Bourdeaudhuij I, Deforche B, Cardon G. Changes in physical activity during the transition from primary to secondary school in Belgian children: what is the role of the school environment? BMC Public Health. 2014;14(1):261.
16. De Baere S, Lefevre J, De Martelaer K, Philippaerts R, Seghers J. Temporal patterns of physical activity and sedentary behavior in 10-14 year-old children on weekdays. BMC Public Health. 2015;15(1):791.

17. Marks J, Barnett LM, Strugnell C, Allender S. Changing from primary to secondary school highlights opportunities for school environment interventions aiming to increase physical activity and reduce sedentary behaviour: a longitudinal cohort study. Int J Behav Nutr Phys Act. 2015:12(1):59.

18. Harding SK, Page AS, Falconer C, Cooper AR. Longitudinal changes in sedentary time and physical activity during adolescence. Int J Behav Nutr Phys Act. 2015;12(1):44.

19. Corder K, Sharp SJ, Atkin AJ, Griffin SJ, Jones AP, Ekelund U. Change in objectively measured physical activity during the transition to adolescence. Br J Sports Med. 2015;49(11):730-6.

20. Brooke HL, Atkin AJ, Corder K, Ekelund U, van Sluijs EM. Changes in timesegment specific physical activity between ages 10 and 14 years: a longitudinal observational study. J Sci Med Sport. 2014;19(1):29-34.

21. Morton KL, Corder K, Suhrcke M, Harrison F, Jones AP, van Sluijs EMF, et al. School polices, programmes and facilities, and objectively measured sedentary time, LPA and MVPA: associations in secondary school and over the transition from primary to secondary school. Int J Behav Nutr Phys Act. 2016;13(1):54.

22. Klinker C, Schipperijn JJ, Kerr JJ, Ersbø\|l AKA, Troelsen JJ. Context-specific outdoor time and physical activity among school-children across gender and age: using accelerometers and GPS to advance methods. Front Publ Health. 2014;2(20):1-15.

23. Klinker CD, Schipperijn J, Toftager M, Kerr J, Troelsen J. When cities move children: development of a new methodology to assess context-specific physical activity behaviour among children and adolescents using accelerometers and GPS. Health Place. 2015;31:90-9.

24. Perchoux C, Chaix B, Cummins S, Kestens Y. Conceptualization and measurement of environmental exposure in epidemiology: accounting for activity space related to daily mobility. Health Place. 2013;21:86-93.

25. Giles-Corti B, Timperio A, Bull F, Pikora T. Understanding physical activity environmental correlates: increased specificity for ecological models. Exerc Sport Sci Rev. 2005;33(4):175-81.

26. Goodman A, Mackett RL, Paskins J. Activity compensation and activity synergy in British 8-13year olds. Prev Med. 2011;53(4):293-8.

27. Prince SA, Adamo KB, Hamel ME, Hardt J, Gorber SC, Tremblay M. A comparison of direct versus self-report measures for assessing physical activity in adults: a systematic review. Int J Behav Nutr Phys Act. 2008:5(1):56.

28. Craggs C, Corder K, Van Sluijs EM, Griffin SJ. Determinants of change in physical activity in children and adolescents: a systematic review. Am J Prev Med. 2011;40(6):645-58

29. Epstein LH, Paluch RA, Coleman KJ, Vito D, Anderson K. Determinants of physical activity in obese children assessed by accelerometer and selfreport. Med Sci Sports Exerc. 1996;28(9):1157-64

30. Sallis JF, Saelens BE. Assessment of physical activity by self-report: status, limitations, and future directions. Res Q Exerc Sport. 2000;71(sup2):1-14.

31. McCrorie PR, Fenton C, Ellaway A. Combining GPS, GIS, and accelerometry to explore the physical activity and environment relationship in children and young people - a review. Int J Behav Nutr Phys Act. 2014;11(1):93.

32. Spence JC, Lee RE. Toward a comprehensive model of physical activity. Psychol Sport Exerc. 2003:4(1):7-24.

33. Kremers SP, De Bruijn G-J, Visscher TL, Van Mechelen W, De Vries NK, Brug J. Environmental influences on energy balance-related behaviors: a dualprocess view. Int J Behav Nutr Phys Act. 2006;3(1):9.

34. Ball K, Timperio AF, Crawford DA. Understanding environmental influences on nutrition and physical activity behaviors: where should we look and what should we count? Int J Behav Nutr Phys Act. 2006;3(1):33.

35. Lachowycz K, Jones AP. Towards a better understanding of the relationship between greenspace and health: development of a theoretical framework. Landsc Urban Plan. 2013;118:62-9.

36. Rainham D, McDowell I, Krewski D, Sawada M. Conceptualizing the healthscape: contributions of time geography, location technologies and spatial ecology to place and health research. Soc Sci Med. 2010;70(5):668-76.

37. Remmers T, Thijs C, Ettema D, de Vries S, Slingerland M, Kremers S. Critical hours and important environments: relationships between afterschool physical activity and the physical environment using GPS, GIS and 
accelerometers in 10-12-year-old children. Int J Behav Nutr Phys Act. 2019; 16(17):3116.

38. Chaix B, Meline J, Duncan S, Merrien C, Karusisi N, Perchoux C, et al. GPS tracking in neighborhood and health studies: a step forward for environmental exposure assessment, a step backward for causal inference? Health Place. 2013;21:46-51.

39. Jankowska MM, Schipperijn J, Kerr J. A framework for using GPS data in physical activity and sedentary behavior studies. Exerc Sport Sci Rev. 2015; 43(1):48.

40. Carlson JA, Jankowska MM, Meseck K, Godbole S, Natarajan L, Raab F, et al. Validity of PALMS GPS scoring of active and passive travel compared with SenseCam. Med Sci Sports Exerc. 2015;47(3):662-7.

41. Kerr J, Norman G, Godbole S, Raab F, Demchak B, Patrick K. Validating GPS data with the PALMS system to detect different active transportation modes. Med Sci Sports Exerc. 2012;44:647.

42. Statistics Netherlands. CBS Statline the Hague. 2017 [cited 2019 November 15]. Available from: https:/www.volksgezondheidenzorg.info/onderwerp/ sociaaleconomische-status/cijfers-context/opleiding\#node-opleidingsniveaunaar-leeftijd.

43. Department of Research and Statistics: Population and area. Department of Research and Statistics 's-Hertogenbosch. 2016 [cited 2019 November 15]. Available from: https://s-hertogenbosch.buurtmonitor.nl.

44. Duncan S, Stewart TI, Oliver M, Mavoa S, MacRae D, Badland HM, et al. Portable global positioning system receivers: static validity and environmental conditions. Am J Prev Med. 2013;44(2):19-29.

45. Schipperijn J, Kerr J, Duncan S, Madsen T, Klinker CD, Troelsen J. Dynamic accuracy of GPS receivers for use in Health Research: a novel method to assess GPS accuracy in real-world settings. Front Public Health. 2014;2:21.

46. The Physical Acitivty and Location Management (PALMS) 2017 [cited 2017 1st of March]. Available from: https://palms.ucsd.edu:8443/PALMS/.

47. Evenson KR, Catellier DJ, Gill K, Ondrak KS, McMurray RG. Calibration of two objective measures of physical activity for children. J Sports Sci. 2008;26(14): 1557-65.

48. Trost SG, Loprinzi PD, Moore R, Pfeiffer KA. Comparison of accelerometer cut points for predicting activity intensity in youth. Med Sci Sports Exerc. 2011;43(7):1360-8.

49. Cain KL, Sallis JF, Conway TL, Van Dyck D, Calhoon L. Using accelerometers in youth physical activity studies: a review of methods. J Phys Act Health. 2013;10(3):437-50

50. Remmers T, Van Kann D, Thiis C, de Vries S, Kremers S. Playability of schoolenvironments and after-school physical activity among 8-11 year-old children: specificity of time and place. Int J Behav Nutr Phys Act. 2016;13(1):82.

51. Cooper AR, Page AS, Wheeler BW, Hillsdon M, Griew P, Jago R. Patterns of GPS measured time outdoors after school and objective physical activity in English children: the PEACH project. Int J Behav Nutr Phys Act. 2010;7(1):31.

52. Arundell L, Ridgers ND, Veitch J, Salmon J, Hinkley T, Timperio A. 5-year changes in afterschool physical activity and sedentary behavior. Am J Prev Med. 2013;44(6):605-11.

53. Van Kann DH, Adank AM, van Dijk ML, Remmers T, Vos SB. Disentangling physical activity and sedentary behavior patterns in children with low motor competence. Int J Behav Nutr Phys Act. 2019;16(20):3804.

54. Rowland TW. The biological basis of physical activity. Med Sci Sports Exerc. 1998:30(3):392-9.

55. Gomersall SR, Rowlands AV, English C, Maher C, Olds TS. The ActivityStat hypothesis. Sports Med. 2013;43(2):135-49.

56. Van Stralen MM, Yildırım M, Wulp A, Te Velde SJ, Verloigne M, Doessegger A .... Chinapaw MJ. Measured sedentary time and physical activity during the school day of European 10-to 12-year-old children: the ENERGY project. J Sci Med Sports. 2014;17(2):201-6.

57. Ahamed Y, Macdonald H, Reed K, Naylor P-J, Liu-Ambrose T, Mckay H. School-based physical activity does not compromise children's academic performance. Med Sci Sports Exerc. 2007;39(2):371-6.

58. Dwyer T, Sallis JF, Blizzard L, Lazarus R, Dean K. Relation of academic performance to physical activity and fitness in children. Pediatr Exerc Sci. 2001;13(3):225-37.

59. Trudeau F, Shephard RJ. Physical education, school physical activity, school sports and academic performance. Int J Behav Nutr Phys Act. 2008;5(1):10.

60. Chastin SF, Palarea-Albaladejo J, Dontje ML, Skelton DA. Combined effects of time spent in physical activity, sedentary behaviors and sleep on obesity and cardio-metabolic health markers: a novel compositional data analysis approach. PLoS One. 2015;10(10):1-37.
61. Ridgers ND, Salmon J, Parrish AM, Stanley RM, Okely AD. Physical activity during school recess: a systematic review. Am J Prev Med. 2012;43(3):320-8.

62. Dessing D, De Vries SI, Graham JM, Pierik FH. Active transport between home and school assessed with GPS: a cross-sectional study among Dutch elementary school children. BMC Public Health. 2014;14(1):227.

63. Stewart T, Duncan S, Schipperijn J. Adolescents who engage in active school transport are also more active in other contexts: a space-time investigation. Health Place. 2017;43:25-32.

64. Treuth MS, Schmitz K, Catellier DJ, McMurray RG, Murray DM, Almeida MJ, et al. Defining accelerometer thresholds for activity intensities in adolescent girls. Med Sci Sports Exerc. 2004;36(7):1259.

65. Trost SG, Owen N, Bauman AE, Sallis JF, Brown W. Correlates of adults' participation in physical activity: review and update. Med Sci Sports Exerc. 2002;34(12):1996-2001

\section{Publisher's Note}

Springer Nature remains neutral with regard to jurisdictional claims in published maps and institutional affiliations.
Ready to submit your research? Choose BMC and benefit from:

- fast, convenient online submission

- thorough peer review by experienced researchers in your field

- rapid publication on acceptance

- support for research data, including large and complex data types

- gold Open Access which fosters wider collaboration and increased citations

- maximum visibility for your research: over $100 \mathrm{M}$ website views per year

At $\mathrm{BMC}$, research is always in progress.

Learn more biomedcentral.com/submissions 